\title{
Making place for local food: Reflections on institutional procurement and the Alberta Flavour Learning Lab
}



PLACE-BASED FOOD SYSTEMS CONFERENCE: Making the Case, Making it Happen August 9-10th, 2018

\author{
Michael C. Granzow ${ }^{a *}$ and Mary A. Beckie ${ }^{b}$ \\ University of Alberta
}

Submitted December 15, 2018 / Revised March 28, May 9, and July 22, 2019 / Accepted July 24, 2019 /

Published online August 26, 2019

Citation: Granzow, M. C., \& Beckie, M. A. (2019). Making place for local food: Reflections on institutional procurement and the Alberta Flavour Learning Lab. Journal of Agriculture, Food Systems, and Community Development, 9(Suppl. 1), 215-229. https://doi.org/10.5304/jafscd.2019.091.042

Copyright (C) 2019 by the Authors. Published by the Lyson Center for Civic Agriculture and Food Systems. Open access under CC-BY license.

\begin{abstract}
Part case study, part reflective essay, this paper examines questions of place and scale in relationship to local food initiatives and, in particular, institutional procurement. A recent emphasis on "place-based" rather than "local" food systems presents an opportunity to ask, What would local food look like here? The Canadian province of Alberta is a unique place defined by a set of geographical, historical, and cultural relationships and connections around food. Through the case of the Alberta Flavour Learning Lab (Alberta Flavour), an institutional procurement initiative

a * Corresponding author: Michael Granzow, Department of Sociology; 5-21 HM Tory Building, University of Alberta; Edmonton Alberta T6G 2H4 Canada; +1-780-245-7946; granzow@ualberta.ca

b Mary A. Beckie, Faculty of Extension, 10230 Jasper Avenue; Edmonton, Alberta T5J 4P6 Canada; +1-780-492-5153; mary.beckie@ualberta.ca
\end{abstract}

\section{Funding Disclosure}

We thank FLEdGE for making this research possible and thank Mitacs for providing matching funding. focused on "scaling up" local food, we discuss how an increased emphasis on context and place activates strategic directions for thinking about food system change. We consider Alberta Flavour as a site of strategic localism that involves actively crafting a scale of local food that functions within a particular context. Rather than reinforcing divides between conventional and alternative food systems, Alberta Flavour interfaces between the broader values of the local food movement and the current realities of Alberta's agri-food landscape and culture. We argue that the initiative's hybrid and pragmatic approach to "getting more local food on more local plates," while not radical, nonetheless contributes to positive food system change through "transformative incrementalism" (Buchan, Cloutier, \& Friedman, in press).

\section{Keywords}

Alberta Flavour Learning Lab, Institutional Procurement, Scaling up, Local Food, Transformative Incrementalism, Reflexive Localism, Strategic Localism, Place-Based Food 


\section{Introduction}

When people think about the "local" in "local food," they tend to think about proximity-the geographical distance between field and fork. The "100-mile diet" and the "food mile," for example, capture this location-based understanding of local food. As the name suggests, local food initiatives are defined largely by efforts to decrease food miles, increase local capacity and economic benefits, and improve food security. Such localization efforts are commonly understood, whether explicitly or not, as political - a response to an unsustainable and globalized food system defined by heavy reliance on agrochemicals, fossil fuels, cheap labor, and mobility of products and capital in the global marketplace. This has resulted in a global versus local food imaginary that continues to frame belief and action for many in the food movement. Discussing the U.S. context, Dupuis and Goodman (2005) note that a "normative localism places a set of pure, conflict-free local values and local knowledges in resistance to anomic and contradictory capitalist forces" (p. 359). Indeed, "local" has become more or less synonymous with resistance.

However, this tidy global versus local political imaginary fails to map onto the complexity and messiness of contemporary life. The assumption that localizing food systems necessarily represents a social and ecological good against the evils of globalization has been described by Born and Purcell (2006) as a "trap." This is not to deny or diminish the potential value of localizing food systems, but rather to acknowledge the myriad factors that must be considered when evaluating the politics of any scale of food system (Fraser, 2010; Harvey, 1996; Hinrichs, 2003; Mansfield, 2005). For example, well-intended local boosterism may result in a "defensive localism" that blinds itself to the plight of people and places on the margins.

A recent turn towards talk of both regional and place-based rather than local food systems presents an opportunity to reflect on the commonly assumed link between local and sustainable, and invites us to ask how an increased emphasis on context and place might activate new and productive directions for thinking about food systems and political possibility. We take the idea of "placebased" as an invitation to reflect theoretically on the relationship between food, scale, and place, with a focus on the western Canadian province of Alberta. In particular, we look at the case of the Alberta Flavour Learning Lab (Alberta Flavour), a community of practice ${ }^{1}$ formed in 2014 in the Edmonton Metropolitan Region, focused on scaling up institutional local food procurement (Alberta Flavour, n.d.). The initiative is the only one of its kind in the province, involving a diverse group of participants, ${ }^{2}$ including institutional food buyers, distributors, processors, producers, retailers, researchers, and government representatives (Beckie, Hedberg, \& Radies, 2019). The members of Alberta Flavour convene around the shared goal of creating "a positive community impact by getting more local food on more local plates" (Beckie et al., 2019, p. 157) through scaling up institutional local food procurement.

The goal of institutional procurement is to leverage the purchasing power of anchor institutions, such as hospitals and schools, in order to generate new economies of scale that create benefits throughout the local supply chain and the wider community (Beckie et al., 2019; Friedmann, 2007; Reynolds \& Hunter, 2017). Institutional procurement initiatives exist, however, in a somewhat ambiguous space between conventional and transformative food systems, leaving some scholars asking how much of an alternative they really offer (Allen \& Guthman, 2006; DeLind, 2011). In the spirit of "reflexive localism" (DuPuis \& Goodman, 2005), we consider Alberta Flavour as a "key case" (Thomas, 2011) that illustrates some of the debates and tensions involved in scaling up local food. Rather than something to be avoided or casually glossed over, we pursue these apparent tensions

\footnotetext{
${ }^{1}$ Wenger (2015) defines communities of practice as "groups of people who share a concern or a passion for something they do and learn how to do it better as they interact regularly."

${ }^{2}$ Members of Alberta Flavour include Northlands Agriculture Society, Alberta Agriculture and Forestry, Alberta Health Services, Covenant Health, the City of Edmonton, Shaw Conference Centre, Erdmann's Gardens and Greenhouses, the University of Alberta, Northern Alberta Institute of Technology, MacEwan University, Aramark, Sysco, and Gordon Food Services.
} 
and contradictions as an opportunity for critical reflection and productive self-critique.

As regular participants in Alberta Flavour, we are uniquely positioned to reflect on the origins and development of the initiative. The second author, a sustainable agriculture and food studies scholar at the University of Alberta, has been affiliated with Alberta Flavour since its inception in 2014. She has been directly involved in conducting research on this evolving community of practice, including the annual measurement and evaluation of institutional local food purchases, as well as overseeing the development of web and social media presence for the initiative. The first author, a Ph.D. candidate in sociology at the University of Alberta, has worked as a research intern with Alberta Flavour since 2017. His role has involved profiling local food initiatives, managing social media accounts, and developing web content.

We consider Alberta Flavour a particular scaling and emplacement of local food that, through its focus on institutional procurement throughout a politically delineated territory, aims to scale up the benefits of local food through forging strategic alliances. In addition, we reflect on Alberta Flavour as a re-negotiating of Alberta's place image where large-scale, export- oriented industrial agriculture, and in particular Alberta beef, has been dominant. Considering place as process rather than container (Harvey, 1996; Massey, 2005; Swyngedouw, 2004), we examine Alberta Flavour as a site of relational place-making (Pierce, Martin, \& Murphy, 2011) in which understandings of Alberta food are reconfigured through an interfacing with Alberta's existing food system and cultural mythos.

In what follows, we outline the methods used for our analysis before turning to an interdisciplinary discussion of place and scale in relation to local food. Employing a constructivist analytical framework marked by an emphasis on the processes by which place and scale are continually made and remade, we consider Alberta Flavour as a strategic intervention into Alberta's unique local food landscape. We go on to consider the politics of up-scaling, to address critiques of institutional procurement, and to complicate distinctions between conventional and alternative food systems. We conclude by situating Alberta Flavour's efforts as an example of transformative incrementalism (Buchan et al., in press), presenting the initiative's policy of scaling up through the development of cross-sector alliances and ambivalent messaging as a tactic towards the goal of broader food system change.

\section{Methods}

This paper draws on the methodological approach of self-ethnography (Alvesson, 2003) to study a key case: the scaling-up of local food in Alberta. As Thomas (2011) writes, "the key-ness... of the case is manifested in its capacity to exemplify the analytical object of the inquiry" (p. 514). Alberta Flavour is a novel local food initiative in the province, but one that also represents a broader trend of scaling up local food through institutional procurement occurring across North America (Fitch \& Santo, 2016; Reynolds \& Hunter, 2017).

Our positionality as participants in Alberta Flavour has given us privileged access to our case. We recognize that our involvement in the group inevitably shapes our analysis, both in ways we are conscious of and ways we are not. While we are aware of the methodological challenges that come with insider research (Alvesson, 2003; Bourke, 2014; Brannick \& Coghlan, 2007), we see it as not only a valid approach, but one particularly wellsuited to the aims of this paper. Outlining some advantages of self-study, Alvesson (2003) writes, "self-ethnography may develop reflexivity in relation to one's own organizational practice, thus combining theory and practice, and transcend the border between doing research and being an organizational member in other capacities" (p. 189). We use this paper as an opportunity to reflect on and develop knowledge about Alberta Flavour as a rescaling and placing of local food in Alberta, while at the same time working in other capacities to support the initiative's goals.

We make no claims of impartiality or objectivity in this analysis. On the contrary, we consider our investment and ongoing participation in Alberta Flavour as not only a primary motivation for our research but a methodological strength (Alvesson, 2003). Self-ethnography rejects many of the criteria of traditional ethnography (Alvesson, 2003). According to Alvesson (2003): 
Self-ethnography is a study and a text in which the researcher-author describes a cultural setting to which s/he has a 'natural access', is an active participant, more or less on equal terms with other participants"... The researcher then works and/or lives in the setting and then uses the experiences, knowledge and access to empirical material for research purposes. (p. 174)

While some may see our closeness to our research subject as invalidating (Morse, 1998), such views have come under increasing criticism (Alvesson, 2003; Attia \& Edge, 2017; Brannick \& Coghlan, 2007). No researcher can observe from an Archimedean point outside of a subjective position. Acknowledgment of this fact is evinced by an increasing emphasis on positionality in social research. Part of a broader emphasis on reflexivity, positionality entails consciously situating yourself in relation to research, and reflecting on potential influences and biases.

The following analysis straddles the line between case study and reflective essay, linking personal experiences, insight, and knowledge with data analysis and theoretical discussion. As part of our study, we met numerous times to discuss our perceptions of and experiences with Alberta Flavour. We also met with and interviewed other members of Alberta Flavour. These meetings involved self-reflection on key moments in Alberta Flavour history, including the group's defining of "local food." In addition, we analyzed and reflected on Alberta Flavour's online messaging with a focus on its Twitter feed, looking for connections between local food and place. The first author has managed the Alberta Flavour Twitter account since 2017, growing its following to nearly 3000 and sharing approximately 1460 tweets per year. Alberta Flavour's Twitter activity was identified as an important component of the group's collective goal of external storytelling (Beckie et al., 2019). Below, we analyze Alberta Flavour's Twitter messaging as active and ongoing constructing and negotiating of the meaning of local food in the Alberta context. Finally, our study includes an analysis of Alberta Flavour's branding in relation to dominant cultural images and imaginaries of Alberta food.

\section{Placing Local Food}

The food movement is a response to a globalized agri-food system in which food has been transformed into a commodity like any other. It can be understood as a countermovement defined by efforts to re-embed food within both ecological and social processes (Raynolds, 2010). The local food movement, in particular, has been framed by a discourse of embeddedness (Hinrichs, 2000), challenging the instrumentalism of conventional food systems and promoting more direct relationships between producers and consumers.

However, much scholarship analyzing the connection between local food systems and social embeddedness fails to reflect in much depth on the idea and role of place. If "local" emphasizes spatial proximity, "place" includes the cultural attachments, meanings, and practices associated with, but not necessarily bounded by, particular locations. While it can be said that location and context are aspects of place, place also includes how people relate to, identify with, or feel towards particular locales. Beyond this, place is further distinguished by its close relationship to culture, a relationship explored by human and cultural geographers.

Since the 1970s, geographers have been developing a humanist approach based on phenomenological ideas serving as a counterpoint to what was becoming a tendency to overlook place in favor of the abstractions of space (Cresswell, 2015). A crucial contributor to these discussions, Yi-Fu Tuan (1977) refused to divide space from place, emphasizing their close relationship. French philosopher Henri Lefebvre emphasized the dialectical relationship between place and space through the development of his spatial triad (Merrifield, 1993). Drawing on Lefebvre, Shields (1991) uses the term "social spatialisation" to reconcile space and place. Massey (2005) adopts a similar ontological position on the relationship between space and place, but with a particular focus on place. Through descriptions of the "throwntogetherness" and "event" of place, Massey emphasize places as moments of continual negotiation and potential change: "In sharp contrast to the view of place as settled and pre-given, with a coherence only to be disturbed by 'external' forces, places as presented here in a sense necessitate invention; they pose a challenge" 
(p. 141). The apparent stability and coherence of place hide the fact that it is continually renegotiated and thus radically open. It is through this lens that emphasizes the relational aspects of place that we understand Alberta Flavour as engaged in a form of place-making (Pierce et al., 2011).

In the context of the food movement and local-food scholarship, this turn toward placebased thinking has been tied to rejecting a globalized, corporate, and "placeless" food system that emphasizes efficiency, scale, and profit above all else. Food regime scholars have discussed this as the difference between "food from nowhere" and "food from somewhere" (Campbell, 2009;

McMichael, 2009). As Wendell Berry (2015) writes, "The great and characteristic problem of industrial agriculture is that it does not distinguish one place from another. In effect, it blinds its practitioners to where they are. It cannot, by definition, be adapted to local ecosystems, topographies, soils, economies, problems, and needs" (para. 4).

DeLind (2011) argues that rooting local food in place would result in a "deeper, more holistic description of local processes, voices, and land- scapes (natural, cultural and political)" (p. 280). While the tendency has been to prioritize social and ecological embeddedness, it is also important to consider the cultural embeddedness of local food initiatives in order to develop robust placebased food systems (Feagan, 2007). This is true even when the cultural context in question does not align neatly with the predominant values of the local food movement, such as in Alberta.

If, as Allen, FitzSimmons, Goodman, and Warner (2003) note, "the local is not everywhere the same," a central question for local food advocates is, "what does local mean here?" And, perhaps more pertinently, "what might local mean here?" Throughout this paper, we ask, what is Alberta food? Alberta is not just a political territory or geographical setting of local food, but a unique place in the Canadian context defined by a set of historical and cultural relationships around, and connections to, food. While an in-depth study of food culture in Alberta goes beyond the purview of this paper, we take a moment to consider the idea of place-based food in a province where cattle, commodity crops, and cowboy culture prevail.

\section{Figure 1. Alberta, Canada}

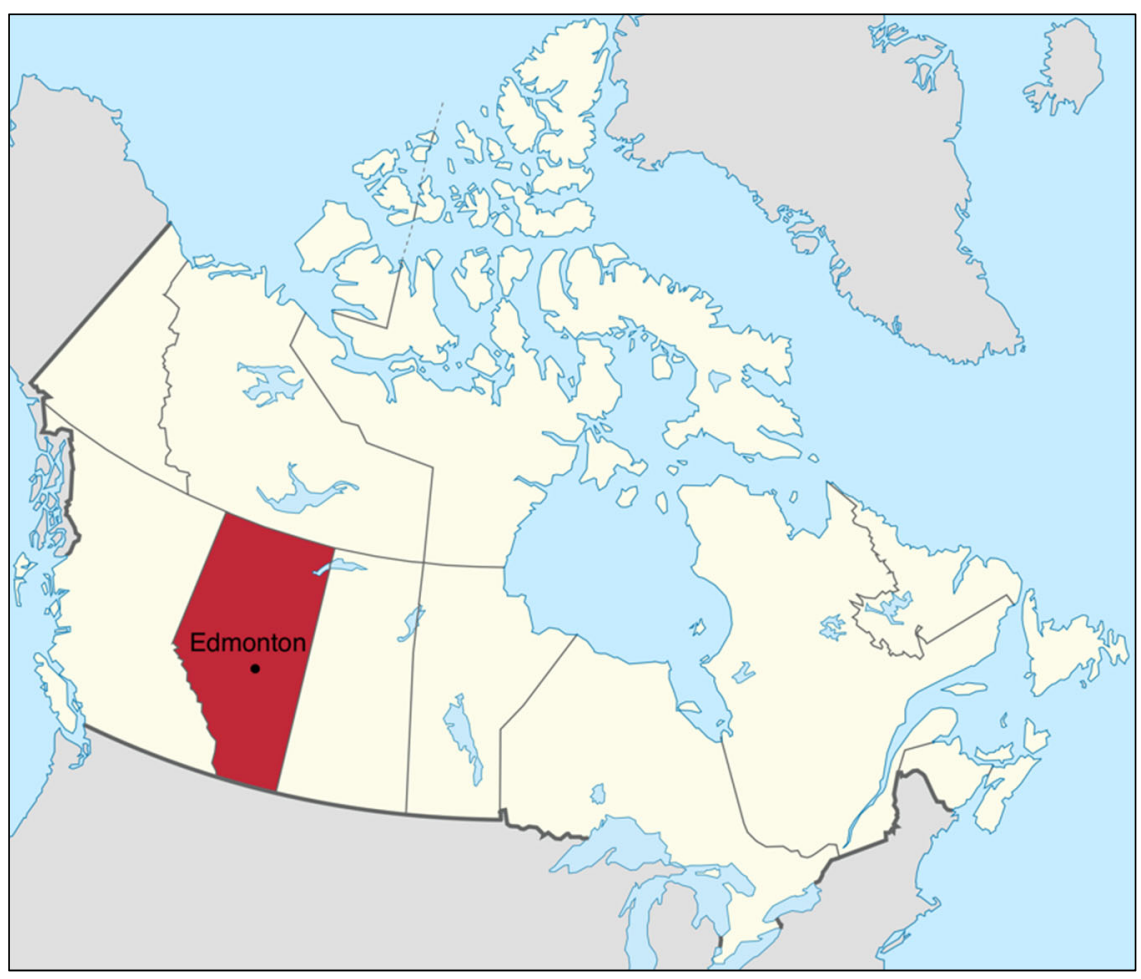

\section{Local Food in Alberta}

Alberta (population 4,286,134; Figure 1) has a total land area of 163 million acres (66 million hectares), but only 51 million acres (21 million ha, or $32 \%$ ) are used for agriculture, with 26 million acres (11 million ha) in native rangeland or tame pasture and 25 million acres (10 million ha) in annual crop production (Statistics Canada, 2017). Agriculture in the province is dominated by large-scale, export-oriented livestock and crop operations; although interest in selling into local markets is growing, currently only 2062 farms or $5.1 \%$ of the total in the province are selling direct (Alberta Agriculture and 
Forestry [AAF], 2018). This percentage is below the national average (12\%) and provincially is the second-lowest, after Saskatchewan (3.8\%) (Statistics Canada, 2017). Farms in Alberta selling into local markets are distributed throughout the province, so no one geographic area dominates, but clustering can be seen around large urban centers, particularly Calgary (pop. 1,240,000), in southern Alberta, and Edmonton (pop. 980,000), the provincial capital in central Alberta (Kienlen \& Blair 2018; Statistics Canada, 2017). These farms are also distributed across all types of farming operations (i.e., crop, livestock, horticulture). Additionally, although there is significant geographic distance (from north to south and east to west) in Alberta, the profile of what can be grown in the province does not change that significantly, regardless of location. However, certain types of agricultural production are better suited to some regions than others; for example, commercial-scale vegetable production is concentrated in central and southern Alberta, which has a longer growing season and more frost-free days than northern regions.

Consistent with the global trend, consumer demand for local food is increasing significantly in Alberta (AAF, 2016). In 2016, the total market value estimate for farmers markets, farm retail, and local food restaurants was CA $\$ 1.624$ billion, quadruple that of 2004 (AAF, 2016). Currently, growth in demand exceeds supply; Christine Anderson, a local food specialist with the department of Alberta Agriculture and Forestry Explore Local Division, states that "there's room for plenty more [farmers]" to capture benefits associated with this trend (Kienlen \& Blair, 2018). Local food in Alberta is defined by AAF as "food grown, made and/or harvested in Alberta and then marketed in Alberta" (Government of Albert, n.d., "Engagement," bullet 1). Using this regional framework, as opposed to the popular "100 mile" association, is beneficial given the context described above.

\section{Alberta Terroir}

The idea that place can be tasted is denoted by the French term terroir. With most understandings of terroir, "the physical environment (soil, weather, topography), not the tiller of the soil, the shepherd, or the vintner, is the primary source of the distinctive tastes of French wine and cheese" (Trubeck, 2008, p. 20). As Trubeck further discusses, however, terroir has also always been a strategic framing of the relationship between food and place propagated through the efforts of "tastemakers" and "taste producers" (p. 21).

Canada Beef, ${ }^{3}$ a national industry lobby group, has recently taken up a vocabulary of terroir as a marketing tool. The director of the Canadian Beef Centre of Excellence is quoted on its website: "Where grape vines grow, the climate, the soil, how vines are tied and tended to; all these factors affect how a wine will taste. Canadian beef has a parallel story to be told. Raised in the great outdoors of Canada's varying landscapes, excellence in Canadian beef is shaped by the terroir on which the cattle are reared" (Canada Beef, n.d., para. 2). In contrast to this recent national marketing initiative, the rise and influence of Alberta beef has had little to do with terroir, relying on a much different sociocultural configuration of food and place-one that has relied on the forging of a link between beef and a particular image and mythology of the Canadian west (Blue, 2008).

Ask most Albertans about Alberta food, and you will likely hear about beef. If you spend some time in the province, you may even see "I love Alberta beef" on a nearby bumper sticker. Alberta is beef country, with the largest number of cattle in Canada (Statistics Canada, 2017). Gwendolyn Blue (2008) of the University of Calgary recounts how Alberta beef came to be a "defining feature of Albertan identity" (p. 70). "“Alberta beef does not simply refer to a geographically located agricultural commodity; rather, in very complex ways, it is bound up with regional identity" (p. 73). With Albertans consuming $16 \%$ or 117,128 tons of the Alberta beef produced in 2017 (AAF, 2018), it is not a stretch to say that beef is an integral part of the province's "local" food system. But, as Blue (2008) reports, the rise of Alberta beef has had little to do with the values of the local food movement and a lot to do with culture, community, and sense of place. Alberta beef has come to stand in 
for a "cultural mythos" in which Alberta is "portrayed as a maverick agrarian region that is distinct, politically, socially and economically, from the rest of Canada" (Blue, 2008, p. 74). Despite the increasing urbanization of the province, "the image of Alberta as an agrarian culture alienated from, and at times under siege by the rest of the nation still captures the public imaginary" (Blue, 2008, p. 75).

The case of Alberta beef complicates simplistic narratives of local food in two ways. First, linking Alberta with beef as analyzed by Blue (2008) can be considered an example of defensive localism, whereby a food product comes to symbolize a conservative identity that stands in opposition to other cultures and peoples. Second, this case challenges the idea that local food exists distinct from and in opposition to conventional, export-oriented food systems. While Alberta beef is both produced and widely consumed in the province (Alberta Agriculture, 2018), it remains largely oriented towards international markets. Moreover, in terms of climate change beef is widely understood to be one of the worst offenders (Gerber et al., 2013; Natural Resources Defense Council [NRDC], 2017). By highlighting how a food may be simultaneously considered local while also being enmeshed in conventional, export-oriented food systems, we set the stage for our analysis of Alberta Flavour as a strategic intervention in and reconfiguring of the idea and image of local food in the province.

\section{Re-scaling Local Food}

Spatial concepts such as local, scale, and place, are not pre-existing categories but are themselves actively constructed in a wide array of contexts. Regarding the question of scale, Smith (1995) writes, "Geographical scales are the product of economic, political, and social activities and relationships; as such they are as changeable as those relationships themselves... Scale is the geographical organizer and expression of collective social action" (p. 60). As we have suggested, "local" is not a neutral description of proximity, but a contingent socio-spatial product that expresses and reproduces certain social, political, and economic arrangements. Our analysis of Alberta Flavour is grounded in a constructionist view that rejects fixed conceptions of "local," "regional" and "global" and recognizes both the contingency and the politics of scale (Born \& Purcell, 2006; Fraser, 2010). As Winter states, "the turn to local food may cover many different forms of agriculture, encompassing a variety of consumer motivations and giving rise to a wide range of politics (in Dupuis \& Goodman, 2005, p. 362).

Scale is a central concept for Alberta Flavour; indeed, the organization describes its efforts as scaling up local food toward the goal of getting "more local food on more plates" (Alberta Flavour, n.d., para. 8). However, as others have pointed out, scaling up is never a uniform expansion, but an uneven reterritorialization. It would be naive to assume that scaling up local food necessarily generates a proportionate expansion of the commonly reported benefits of local food. Rather, any such expansion of benefits is likely to be distributed unevenly across time and space; in addition, "jumping scale" also involves new socio-spatial configurations that may, in fact, contradict or counteract the foundational goals of the movement of which the organization is a part. Rather than assuming, for example, that "bigger is better," human geographers, in particular, have implored that we take the politics of scale seriously.

Fraser (2010) asks, "“what is the most effective scale for organizing?” (p. 339). The local food movement's version of this question is, "What scale is most effective in positively reforming the current food system?" In addition to adhering to particular ideas of local, local food initiatives, whether they themselves recognize it or not, are always involved in their production-that is, in the process of enacting the idea of the local. Fraser's (2010) concept of "scalecraft" highlights the now widely accepted view that scale is a meaningful and political social product, re-focusing attention on the craft involved with such a process.

To say that Alberta Flavour is a moment of scalecraft (Fraser, 2010) is to emphasize the ways in which it is an active and strategic production of the local scale, and also to point out that such a construction has particular political effects:

Human actors, whether individuals, social groups, or governing bodies (such as governments or state agencies) 'produce' and 'use' 
scale in all manner of attempts to create some sort of advantage, to establish associations, connections, or solidarities across social divides, or to represent their interests (to be heard or seen) amidst oppressive or otherwise difficult conditions. (Fraser, 2010, p. 332)

For Alberta Flavour, what began with a simple question of how to get "more local food on more local plates" set in motion a group of relationships and connections that has resulted in a viable version of the local scale. We turn now to looking at the definition of local generated by Alberta Flavour participants as a foundational moment of scalecraft.

\section{Defining Local: Two out of Three Ain't Bad} Definitions of local are strategic constructs- they differ across time and space depending on organizational goals and the interests of actors involved. Regardless of what individuals might think about local food, the local scale must be operationalized in ways that function for specific initiatives. From the beginning, Alberta Flavour was aimed at getting large players in Alberta's food system to the table as participants in the local food conversation. Enrolling institutional actors and private distribution corporations into a collaborative network focused on increasing local food procurement is no easy task, and it became clear early on that scaling up local food would require a strategic definition of local.

In 2014 members of Alberta Flavour came up with three criteria for local food: (1) ingredients grown in Alberta, (2) food processed in Alberta, and (3) business owned by Albertans. Instead of requiring all three criteria, it was decided that two out of three were sufficient for a food item to be considered local. This definition prioritizes the development of a regional food system, foregrounding the political territory of Alberta. It is important to note, however, that this definition also allows for a degree of fluidity in order to accommodate the extra-local geographies and players that shape our current food system. Illustrating the point by Hinrichs (2003) that "boundaries between the local and the non-local are now borders, rather than barricades" (p. 37), Alberta Fla- vour's definition aims to translate the concept of "local" into a set of criteria that resonates with institutions and corporations. It translates what might be understood by large players in the food system as a chimeric ideal into something actually achievable.

The large institutions at the core of Alberta Flavour require large volumes of food that are consistently available and therefore predominantly depend on established purchasing channels controlled by large distributors such as Sysco and Gordon Food Services (GFS). Alberta Flavour also includes participants from Aramark, a multinational food service provider currently under contract with the University of Alberta. Including such participants in Alberta Flavour has been crucial to linking large institutions into a local food equation. Sysco and GFS have participated regularly in group meetings and have reorganized their product inventory to reflect Alberta Flavour's definition of local food. This initial work proved instrumental in identifying local foods available through major distributors and provided essential data for Alberta Flavour's initial baseline study of the institutions' local food purchasing.

With the increased appetite for local food in Alberta, there exists an unprecedented opportunity to scale up production and distribution. Flexible, regionally focused definitions of local food are advantageous for larger institutions and companies looking to benefit from the rising tide of local food. However, such flexible definitions of local food have been criticized by food scholars and activists as a kind of gerrymandering - a convenient shifting of boundaries designed to serve the interests of actors unwilling or unable to assent to more limited but arguably more effective definitions of local (DeLind, 2011). The worry for DeLind is that "the local food movement...may be distancing itself from its systemic roots, exchanging rhetoric for the harder work of contextual analysis" (p. 275).

Alberta Flavour might be seen as an opportunity for corporations that continue to have large stakes in conventional food systems to gain credibility and visibility and take advantage of the added value that comes with local branding. Moreover, Alberta Flavour's flexible definition of local has 
resulted in some questionable product promotions, such as that of Lay's potato chips. Lay's chips are processed in Taber, Alberta and are made from potatoes grown in the province. This means that according to Alberta Flavour's criteria, a product produced by Frito Lay, a subsidiary of Pepsi, is local. ${ }^{4}$ Promoting Lay's potato chips as local food seems like precisely the kind of "local-washing" (Roberts, 2011) that local food initiatives may wish to avoid. When large corporations co-opt "local," (re)branding and marketing their products in the race to capture market share and stay competitive in a rapidly evolving global food system, they detract from a movement grounded in deeper social and environmental values (Cleveland, 2014). If scaling up local food through institutional procurement means enrolling multinational companies beholden to the bottom line, perhaps it is a sign that we are indeed "hitching our wagons to the wrong stars" (DeLind, 2011). DeLind concludes her discussion of "the Wal-Mart emphasis" with Audre Lorde's acute observation that "the master's tools will never dismantle the master's house" (p. 278). While a truly radical alternative to the current food system may require not only new distribution systems, but a completely re-imagined economic and political system, we propose that "working with the master's tools" is not necessarily antithetical to this cause, and may contribute to transformational change.

\section{Bridging the Divide: Strategic Localism and the Politics of Alberta Flavour}

While Alberta Flavour strives towards a set of values and goals broadly associated with the food movement (Beckie et al., 2019), it relies on buy-in from institutions and companies bound by market logics. Exploring this kind of tension, Fitch and Santos (2016) have commented on the tendency for institutional procurement initiatives to prioritize economic viability over other sustainability factors. Would institutional procurement initiatives such as Alberta Flavour be more effective in contributing to the development of a more sustainable and socially just food movement if they reduced their emphasis on economic viability, thereby dis- engaging from the dominant food system? While some have made arguments suggesting this to be the case (Allen et al. 2003; Hinrichs, 2000), the answer continues to be both uncertain and highly complex (Sonnino \& Marsden, 2006; Smith, 2006). In their analysis of the interactions between innovation networks and their environment, Klerkx, Aarts, and Leeuwis (2010) found that while actors or organizations are inevitably bounded by structural influences, they can nonetheless engage in "effective reformism" (Roep, Van Der Ploeg, \& Wiskerke, 2003).

Rather than rejecting the conventional food system, Alberta Flavour emphasizes alignment between a diverse membership working within existing structures towards "transformative incrementalism" (Buchan et al., in press). Whereas transformative change is often associated with sudden and drastic shifts or breaks, Buchan et al. (in press) suggest that such change is also achieved incrementally in institutional contexts, although it is more difficult to observe. The authors emphasize the "slow and cumulative actions" that food system planners engage in toward transformative change (p. 24). Their nuanced discussion of the relationship between change and power mitigates easy categorical distinctions between "conventional" and "alternative" local food initiatives. Smith (2006), skeptical of "unchallenging, middle-of-the-road" (p. 455) innovations that concede to the requirements of existing systems, draws attention to a paradox at the heart of Alberta Flavour: "a niche which is in tune with the incumbent regime will not demand very great changes in sociotechnical practices; whereas radical niches... will not diffuse much at all" (p. 443). In the end, however, Smith highlights the tensions surrounding incremental change while also acknowledging its value. "The main lesson" is:

It is essential for niches to be both radical and reforming. That is, there can be niche elements which can be appropriated by the mainstream relatively easily and which may form a first step towards mildly more sustainable reforms. Meanwhile, the more radical practices will con-

4 For a description of how Lay's has been involved in a local marketing campaign see DeLind (2011, p. 277). 
tinue to be pursued by committed actors within a renewed niche. They remain advocates for more radical systems innovations. (Smith, 2006, p. 455)

Alberta Flavour represents an overarching strategy of hybridity and dialogue. This is true not only in terms of the way it navigates conventional and alternative food systems, but also in terms of the stories it tells about local food in Alberta. As Pratt (2007) argues, developing alternative food systems involves both organizational and discursive strategies (p. 298). In addition to dealing with the logistic challenges of scaling up, local food initiatives benefit from framing their efforts in ways that support their strategic goals. This includes highlighting certain scales of practice and visions of place. Through its branding and Twitter messaging, Alberta Flavour promotes a particular local food story-one that bridges Alberta's cultural and economic investments in conventional, exportoriented agriculture with smaller-scale, urbanfocused, initiatives.

Alberta Flavour's marketing included the development of a logo depicting a fork set against an outline of the province of Alberta (Figure 2). Whether designed with the intention or not, using the silhouette of Alberta in the context of a local food conversation immediately evokes the "I love

\section{Figure 2. The Alberta Flavour Logo}

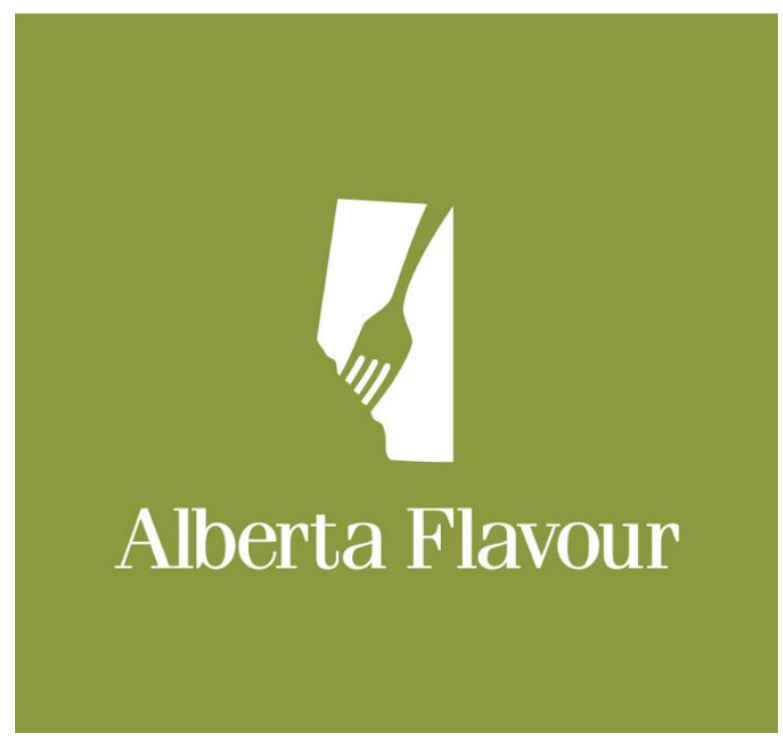

Alberta beef" marketing campaign discussed above. The logo interfaces with the success of this campaign, while also leveraging that success to promote other "local" foods, many of which are commodity crops. The Alberta Flavour logo subtlety frames a local food conversation within both a context of both regional food systems as well as a culture of what many would consider to be unsustainable conventional agriculture. Even in the very nature of its logo, Alberta Flavour aims to tell a unique story around local food in Albertaone that resists the conventional-versus-alternative imaginary that permeates contemporary food politics. This particular story is told and retold daily through both the Alberta Flavour website and its Twitter messaging.

The Alberta Flavour Twitter account (@AlbertaFlavour) is dedicated to telling the story of Alberta Flavour through showcasing local initiatives and advocating for benefits of local food more generally. Alberta Flavour created the hashtag \#ABFoodFacts to help draw attention to and discuss the food landscape in Alberta. This hashtag is usually attached to facts about what foods are being produced and/or processed in the province, with the goal of helping the Alberta food system to be more visible to consumers. These food facts are taken from a variety of publications, including the Canadian Agriculture census and data from AAF. One of the most liked and retweeted \#ABFoodFacts reads: "DYK \#Alberta is the largest honey producing province in \#Canada?!" Another reports that "\#Alberta is the largest \#potato producing province in \#WesternCanada, growing over 1,800,000,000 lbs of potatoes a year." Considered as a whole, the tweets gathered under \#ABFoodFacts are characterized by a strong emphasis on the productive capacity of Alberta, with little said about, for example, the sustainability implications of producing food (local or not) at that scale and for the primary purpose of export.

However, the productivist focus of the \#ABFoodFacts discussion is accompanied by Alberta Flavour's messaging on alternative and urban-focused local food initiatives. For instance, @ AlbertaFlavour regularly reports on topics such as the potential of urban agriculture and foraging, sharing articles from outlets such as City Lab and 
Civil Eats. In addition to promoting the possibility of growing food in the city, such messaging advocates for issues such as permaculture, food hubs, food sovereignty, and social justice. One representative tweet citing a relevant $\mathrm{CBC}$ article reads, "Calling all foodies, gardeners, nature lovers and proponents of pollinators: bee hotels are up for grabs from the Edmonton and Area Land Trust so Edmontonians can help preserve the bee population." As another example, a The [Toronto] Globe and Mail article on urban foraging was retweeted, which celebrated the "incredible variety of food hidden in Alberta's landscape." Alberta Flavour also regularly re-tweets content from Civil Eats, ${ }^{5}$ an online publication emphasizing radical food system change.

These two sides of Alberta Flavour's twitter messaging illustrate the initiative's recognition of the realities of Alberta's agri-food context and its culture. In refusing to play into the divide between rural versus urban or conventional versus alternative food systems, Alberta Flavour opens itself up to the possibility of contradiction. Such apparently confused or ambivalent messaging might be seen as signaling a watered-down food politics that, in attempting to speak to everyone, fails to speak to anyone. However, in a world increasingly defined by the false comforts of a "filter bubble," there is value in online spaces that interface between what is often presented as oppositional visions of local food. Consistent with Mount (2012), who argues that "recognition of hybridity may be a sign of an adaptive, more reflexive localism" (p. 112), Alberta Flavour crafts a story of Alberta food that recognizes local food culture and food values while also bridging a continued urban-rural divide. Through this strategy, Alberta Flavour helps create a common ground for involving more people in the local food conversation.

\section{Conclusion}

Alberta Flavour has an important story to tell. In contrast to a defensive localism that reifies fixed local boundaries, the initiative presents a strategic and pragmatic approach to the question of scaling up local food. As its name suggests, the local food movement was defined in large part by efforts to scale down food systems, re-embedding these systems in community, ecology, and place (Allen, 2008; Renting, Marsden, \& Banks, 2003). As the movement has evolved, however, practitioners and researchers alike have re-evaluated previously held assumptions around scale, calling into question the presumed superiority of local (Allen et al., 2003; Born \& Purcell, 2006; DuPuis \& Goodman, 2005; Hinrichs, 2003; Sonnino, 2010). Alberta Flavour works to scale up the benefits of local food through leveraging the purchasing power of large institutions. Enrolling such institutions in the Alberta context means working with large corporations such as Sysco and Aramark. While the development of such alliances may be criticized for its "Wal-Mart emphasis" (DeLind, 2011), the analysis should not stop there. As we have argued in relation to Alberta Flavour's strategic localism, "working with the master's tools" is not necessarily antithetical to building alternative food futures, but is one tactic in a larger movement towards food system change.

A main strength of capitalism has always been its ability to absorb its own critique, turning potential contradictions or sites of resistance into new sources of accumulation and profit (Marcuse, 1964). Incorporating potentially transformative ideas into existing structures often involves cooptation. DeLind is right to worry that if we let "market potential" and "economic outcomes" (p. 275) guide local food practices and ignore other values (e.g., ecology, culture, biological diversity, etc.) we will be left with a watered-down and consumable commodity approach, hollowed-out of any actual alternative. Yet, as evinced by the case of Alberta Flavour, the line between conventional and alternative food systems is not always clear. As Pratt (2007) writes, these systems "shape each other and often overlap in highly significant ways" (p. 285).

Local food activists and scholars should remain vigilant and not be too quick to celebrate the embracing and scaling up of local food by large corporations. At the same time, working with corporations through models such as institutional pro-

5 https://civileats.com/about/ 
curement does not automatically preclude the possibility of transformative change. Alberta Flavour disrupts local/global and conventional/alternative divides through a strategic localism defined by a rescaling and emplacing of local food in the unique Alberta context. The initiative's hybrid and pragmatic approach to "getting more local food on more local plates," while not radical, nonetheless contributes to a more positive food system through "transformative incrementalism" (Buchan et al., in press).

Alberta Flavour's strategic localism is defined not only by its scalecraft (Fraser, 2010), but also by its emplacing of local food in Alberta. As Tuan (1977) writes, "place exists at different scales. At one extreme, a favorite armchair is a place, at the other extreme the whole earth" (p. 149). While much attention has been given to the construction of place at the level of the nation-state (Anderson, 1991), less is written on the relationship between place and the region (Cresswell, 2015, p. 14; Paasi, 2002). Alberta is both a region and a place defined in large part by commodity exports and a unique cultural mythos exemplified by Alberta beef.

Rather than ignore this cultural context or reject it outright as regressive and antithetical to the local food movement, Alberta Flavour uses branding and social media to interface between agricultural productivism and food system change. If such messaging is at times contradictory, this too can be considered a gesture of dialogue-an opportunity to critically reflect on differing visions of local food in the province. We have framed these efforts as active sites of place-making (Pierce et al., 2011), where ideas about Alberta food and by extension Alberta as a meaningful place are negotiated. Conceiving of "place as event" (Massey, 2005, p. 141), we have positioned Alberta Flavour as an opportunity to intervene constructively in the existing constellation of practices, discourses, and imaginaries linking Alberta with an industrial, exportoriented food-system increasingly recognized to be unsustainable.

\section{Acknowledgments}

This project is part of FLEdGE, a national study of local and sustainable food systems. We thank FLEdGE for making this research possible. We thank Northlands Agricultural Society and, in particular, Director of Agriculture Jessie Radies for her ongoing support and guidance. We would also like to thank Katheryn Lennon for her insights and contributions early in the process. Finally, we thank Madeleine Baldwin and Gary Barron for their thoughtful feedback and suggestions along the way.

\section{References}

Alberta Agriculture and Forestry (AAF). (2018, Aug. 15). Who eats Alberta beef. Olds, AB: Mountain View Gazette. Retrieved from https://www.mountainviewgazette.ca/article/who-eats-alberta-beef-20180815

Alberta Flavour. (n.d.). Why local? http://temp-albertaflavour.nationbuilder.com/why local

Allen, P. (2008). Mining for justice in the food system: Perceptions, practices, and possibilities. Agriculture and Human Values, 25(2), 157-161. https://doi.org/10.1007/s10460-008-9120-6

Allen, P., FitzSimmons, M., Goodman, M., \& Warner, K. (2003). Shifting plates in the agrifood landscape: The tectonics of alternative agrifood initiatives in California. Journal of Rural Studies, 19(1), 61-75. https://doi.org/10.1016/S0743-0167(02)00047-5

Allen, P., \& Guthman, J. (2006). From 'old school' to 'farm-to-school': Neoliberalization from the ground up. Agriculture and Human Values, 23(4), 401-415. https://doi.org/10.1007/s10460-006-9019-z

Alvesson, M. (2003). Methodology for close up studies-Struggling with closeness and closure. Higher Education, 46(2), 167-193. http://lup.lub.lu.se/record/900163

Anderson, B. (1991). Imagined communities: Reflections on the origin and spread of nationalism (Rev. ed.). London, UK: Verso.

Attia, M., \& Edge, J. (2017). Be(com)ing a reflexive researcher: A developmental approach to research methodology. Open Review of Educational Research, 4(1), 33-45. https://doi.org/10.1080/23265507.2017.1300068

Beckie, M. A., Hedberg, L., \& Radies, J. (2019). Creating a local food procurement community of practice: The Alberta Flavour Learning Lab. Canadian Food Studies / La Revue Canadienne Des Études Sur l'alimentation, 6(1), $155-169$. https://doi.org/10.15353/cfs-rcea.v6i1.267 
Berry, W. (2015). Farmland without farmers. The Atlantic. Retrieved from https://www.theatlantic.com/national/archive/2015/03/farmland-without-farmers/388282/

Blue, G. (2008). If it ain't Alberta, it ain't beef. Food, Culture \& Society, 11(1), 69-85. https://doi.org/10.2752/155280108X276168

Born, B., \& Purcell, M. (2006). Avoiding the local trap: Scale and food systems in planning research. Journal of Planning Education and Research, 26(2), 195-207. https://doi.org/10.1177/0739456X06291389

Bourke, B. (2014). Positionality: Reflecting on the research process. The Qualitative Report, 19(33), 1-9. Retrieved from https://nsuworks.nova.edu/tqr/vol19/iss33/3

Brannick, T., \& Coghlan, D. (2007). In defense of being "native": The case for insider academic research. Organizational Research Methods, 10(1), 59-74. https://doi.org/10.1177/1094428106289253

Buchan, R., Cloutier, D. S., \& Friedman, A. (in press). Transformative incrementalism: Planning for transformative change in local food systems. Progress in Planning. https://doi.org/10.1016/j.progress.2018.07.002

Campbell, H. (2009). Breaking new ground in food regime theory: Corporate environmentalism, ecological feedbacks and the 'food from somewhere' regime? Agriculture and Human V alues, 26(4), 309-319. https://doi.org/10.1007/s10460-009-9215-8

Canada Beef. (n.d.). Taste and terroir: A sensory celebration of Canadian beef + Canadian wine. Retrieved August 24, 2019, from https://canadabeef.ca/makeitbeef/taste-and-terroir-a-sensory-celebration-of-canadian-beef-canadian-wine/

Cleveland, D. A. (2014). Balancing on a planet: The future of food and agriculture. Berkeley, CA: University of California Press. https://doi.org/10.1525/california/9780520277410.001.0001

Cresswell, T. (2015). Place: An introduction. Malden, MA: John Wiley.

DeLind, L. B. (2011). Are local food and the local food movement taking us where we want to go? Or are we hitching our wagons to the wrong stars? Agriculture and Human V alues, 28(2), 273-283.

https://doi.org/10.1007/s10460-010-9263-0

DuPuis, E. M., \& Goodman, D. (2005). Should we go "home" to eat? Toward a reflexive politics of localism. Journal of Rural Studies, 21(3), 359-371. https://doi.org/10.1016/j.jrurstud.2005.05.011

Feagan, R. (2007). The place of food: Mapping out the 'local' in local food systems. Progress in Human Geography, 31(1), 23-42. https://doi.org/10.1177/0309132507073527

Fitch, C., \& Santo, R. (2016). Instituting change: An overview of institutional food procurement and recommendations for improvement. Baltimore, MD: Johns Hopkins Center for a Livable Future. Retrieved from https://www.jhsph.edu/research/centers-and-institutes/johns-hopkins-center-for-a-livablefuture/ pdf/research/Instituting-change.pdf

Fraser, A. (2010). The craft of scalar practices. Environment and Planning A: Economy and Space, 42(2), 332-346. https://doi.org/10.1068/a4299

Friedmann, H. (2007). Scaling up: Bringing public institutions and food service corporations into the project for a local, sustainable food system in Ontario. Agriculture and Human Values, 24(3), 389-398. https://doi.org/10.1007/s10460-006-9040-2

Gerber, P. J., Steinfeld, H., Henderson, B., Mottet, A., Opio, C., Dijkman, J., Falcucci, A., \& Tempio, G. (2013). Tackling climate change through livestock- A global assessment of emissions and mitigation opportunities. Rome, IT: Food and Agriculture Organization of the United Nations (FAO). Retrieved from http://www.fao.org/3/a-i3437e.pdf

Government of Alberta. (n.d.). Local food engagement. Retrieved August 24, 2019, from the Alberta website: https://www.alberta.ca/local-food-engagement.aspx

Harvey, D. (1996). Justice, nature, and the geography of difference. Malden, MA: Blackwell.

Hinrichs, C. C. (2000). Embeddedness and local food systems: Notes on two types of direct agricultural market. Journal of Rural Studies, 16(3), 295-303. https://doi.org/10.1016/S0743-0167(99)00063-7

Hinrichs, C. C. (2003). The practice and politics of food system localization. Journal of Rural Studies, 19(1), $33-45$. https://doi.org/10.1016/S0743-0167(02)00040-2

Kienlen, A., \& Blair, J. (2018, July 30). Local food is putting down deep roots. Winnipeg, MB: Alberta Farmer Express. Retrieved from https://www.albertafarmexpress.ca/2018/07/30/local-food-is-putting-down-deep-roots/ 
Klerkx, L., Aarts, N., \& Leeuwis, C. (2010). Adaptive management in agricultural innovation systems: The interactions between innovation networks and their environment. Agricultural Systems, 103(6), 390-400. https://doi.org/10.1016/j.agsy.2010.03.012

Lefebvre, H. (1991). The production of space (Nicholson-Smith, D., Trans.). Oxford, UK: Blackwell.

Mansfield, B. (2005). Beyond rescaling: reintegrating the 'national' as a dimension of scalar relations. Progress in Human Geography, 29(4), 458-473. https://doi.org/10.1191/0309132505ph560oa

Marcuse, H. (1964). One-dimensional man: Studies in the ideology of advanced industrial society. Boston, MA: Beacon Press.

Massey, D. (2005). For space. London, UK: Sage.

McMichael, P. (2009). Banking on agriculture: A review of the World development report 2008.

Journal of Agrarian Change, 9(2), 205-28. https://doi.org/10.1111/j.1471-0366.2009.00203.x

Merrifield, A. (2003). Place and space: A Lefebvrian reconciliation. Transactions of the Institute of British Geographers, 18(4), 516-53. https://doi.org/10.2307/622564

Morse, J. (1998). Designing funded qualitative research. In N. Denzin \& Y. Lincoln (Eds.), Strategies of qualitative inquiry (pp. 56-85). Thousand Oaks, CA: Sage.

Mount, P. (2012). Growing local food: Scale and local food systems governance. Agriculture and Human Values, 29(1), 107-121. https://doi.org/10.1007/s10460-011-9331-0

Natural Resources Defense Council (NRDC). (2017). Less beef, less carbon (Issue paper 16-11-B). New York: NRDC. Retrieved from https://www.nrdc.org/sites/default/files/less-beef-less-carbon-ip.pdf

Paasi, A. (2002). Place and region: Regional worlds and words. Progress in Human Geography, 26(6), 802-811. https://doi.org/10.1191/0309132502ph404pr

Pierce, J., Martin, D. G., \& Murphy, J. T. (2011). Relational place-making: The networked politics of place. Transactions of the Institute of British Geographers, 36(1), 54-70. https://doi.org/10.1111/j.1475-5661.2010.00411.x

Pillow, W. (2003). Confession, catharsis, or cure? Rethinking the uses of reflexivity as methodological power in qualitative research. International Journal of Qualitative Studies in Education, 16(2), 175-196. https://doi.org/10.1080/0951839032000060635

Pratt, J. (2007). Food values: The local and the authentic. Critique of Anthropology, 27(3), 285-300. https://doi.org/10.1177/0308275X07080357

Raynolds, L. T. (2000). Re-embedding global agriculture: The international organic and fair trade movements. Agriculture and Human V alues, 17(3), 297-309. https://doi.org/10.1023/A:1007608805843

Renting, H., Marsden, T. K., \& Banks, J. (2003). Understanding alternative food networks: Exploring the role of short food supply chains in rural development. Environment and Planning A, 35(3), 393-411. https://doi.org/10.1068/a3510

Reynolds, J., \& Hunter, B. (2017). Purchasing power: 10 lessons on getting more local, sustainable, and delicious food in schools, hospitals and campuses. Montreal: J. W. McConnell Family Foundation \& Food Secure Canada. Retrieved from https://ccednet-rcdc.ca/sites/ccednet-rcdc.ca/files/purchasing_power_report2017.pdf

Roberts, W. (2011, Dec. 13). Citywatch: Food's a trip, actually a baker's dozen of trips [Blog post]. Retrieved from http://wayneroberts.ca/archives/778

Roep, D., Van Der Ploeg, J. D., \& Wiskerke, J. S. C. (2003). Managing technical-institutional design processes: Some strategic lessons from environmental co-operatives in the Netherlands. NJAS - Wageningen Journal of Life Sciences, 51(1-2), 195-217. https://doi.org/10.1016/S1573-5214(03)80033-7

Sage, C. (2003). Social embeddedness and relations of regard: Alternative 'good food' networks in south-west Ireland. Journal of Rural Studies, 19(1), 47-60. https://doi.org/10.1016/S0743-0167(02)00044-X

Shields, R. (1991). Places on the margin: Alternative geographies of modernity. New York: Routledge.

Smith, A. (2006). Green niches in sustainable development: The case of organic food in the United Kingdom. Environment and Planning C: Government and Policy, 24(3), 439-458. https://doi.org/10.1068/c0514j

Smith, N. (1995). Remaking scale: Competition and cooperation in prenational and postnational Europe. In H. Eskelinen \& F. Snickars (Eds.), Competitive European peripheries (pp. 59-74). Berlin and Heidelberg, DE: Springer. https://doi.org/10.1007/978-3-642-79955-6 4 
Sonnino, R., \& Marsden, T. (2006). Beyond the divide: Rethinking relationships between alternative and conventional food networks in Europe. Journal of Economic Geography, 6(2), 181-199. https://doi.org/10.1093/jeg/lbi006

Statistics Canada. (2017). Alberta has the most beef cattle in Canada and the second largest total farm area. Ottawa: Statistics Canada. Retrieved from https://www150.statcan.gc.ca/n1/pub/95-640-x/2016001/article/14808-eng.htm

Swyngedouw, E. (2004). Globalisation or 'glocalisation'? Networks, territories and rescaling. Cambridge Review of International Affairs, 17(1), 25-48. https://doi.org/10.1080/0955757042000203632

Thomas, G. (2011). A typology for the case study in social science following a review of definition, discourse, and structure. Qualitative Inquiry, 17(6), 511-521. https://doi.org/10.1177/1077800411409884

Trubeck, A. B. (2008). The taste of place: A cultural journey into terroir. Berkeley: University of California Press.

Tuan, Y. F. (1977). Space and place: The perspective of experience. London: Edward Arnold.

Wenger, E. (2015). Introduction to communities of practice. Retrieved from http://wenger-trayner.com/introduction-to-communities-of-practice/

Winter, M. (2003). Embeddedness, the new food economy and defensive localism. Journal of Rural Studies, 19(1), 23-32. https://doi.org/10.1016/S0743-0167(02)00053-0

Willis, K. S., Frosch, K., \& Struppeck, M. (2014). Re-placing food: Place, embeddedness, and local food. In J. H.-J. Choi, M. Foth, \& G. Hearn (Eds.), Eat, cook, grow: Mixing human-computer interactions with human-food interactions (pp. 153-170). Cambridge, MA: MIT Press. 